\title{
THE ‘RESPONSIBILITY’ FACTOR IN IMAGINING THE FUTURE OF EDUCATION IN CHINA
}

\author{
De Vos, Ellen (1,3); Xin, Xin (2); De Marez, Lieven (3,4); Emmanouil, Marina (1) \\ 1: Department of Industrial Systems Engineering and Product Design, Ghent University; 2: Beijing \\ Normal University; 3: Department of Communication Studies, Research group imec-mict-UGent, Ghent \\ University; 4: imec
}

\begin{abstract}
Design and creativity have been a considerable force for improving life conditions. A lot of effort has been invested in explaining the design process and creativity mainly through the design thinking methodology, but design accountability and responsible actions in the design process are, yet, to be fully explored. The concept of design ethics is now increasingly scrutinized on both the level of business organization and of the individual designer. A 4-day design workshop that involved creativity techniques provided the base to explore responsibility in the fuzzy front end of the design process. The future of education in 2030 was defined as the workshop's theme and fifty-six students from China were asked to create detailed alternative scenarios. A number of imagination exercises, implementation of technological innovations and macro-environment evolutions employed in the workshop are discussed. The aim was to incite moral and responsible actions among students less familiar with creative educational contexts of student-led discovery and collaborative learning. This paper reflects on the use of creativity methods to stimulate anticipation in (non)design students.
\end{abstract}

Keywords: Early design phases, Creativity, Design education, Imagination of the future, China

Contact:

De Vos, Ellen

Ghent University

Industrial Design Engineering Technology

Belgium

ehidvos.devos@ugent.be

Cite this article: De Vos, E., Xin, X., De Marez, L., Emmanouil, M. (2019) 'The 'Responsibility' Factor in Imagining the Future of Education in China', in Proceedings of the 22nd International Conference on Engineering Design (ICED19), Delft, The Netherlands, 5-8 August 2019. DOI:10.1017/dsi.2019.64 


\section{INTRODUCTION}

Creativity has been recognized as a crucial factor in creative and non-creative industries alike (Shalley et al., 2000). The skill of being able to alternate from short-term problem-solving to long-term strategic decision-making is increasingly appreciated, yet, still complex (Gilson and Madjar, 2011). The creative process involves iterations of several behavioral and cognitive steps in problem identification, searching for information widely, trying out new approaches, and implementing multiple ideas (Shalley and Gilson, 2017). With this in mind, exploratory processes at the initial stages of design are a lot more intricate than the overarching concept 'idea generation' may elicit. Csikszentmihalyi and Sawyer $(2014,79)$ state that at first, creativity requires a stage of uncertainty (about the goal), and later on delves into a 'void' when creative insights grow in the subconscious mind. On the matter Markman and colleagues (2012) defined imagination as a mental creation of things (or ideas) not immediately present to the senses. This paper asks which creative tools can elicit imagination in the early stages of the design process.

Imagination is a powerful element in innovation and technological advancement to the point that it has made technology appear as a complete transformer of our lives (Bennett and Maton, 2010) and a cause of some undesired consequences. For instance, there are a lot of ongoing discussions about the many jobs that might disappear due to the added value of these new technologies. In other instances however, emerging technologies (e.g., virtual reality, voice controlled interfaces) have been discussed as providing opportunities to remodel systems on a world scale, such as the system of education. These opportunities are seen to solve specific problems (e.g., open-source textbooks versus expensive tuition fees) or allow a reconsideration of the organization and delivery (of education) as a whole (e.g., big data and machine learning to correct tasks and tests). A second question raised in this research is: what are the questions contemporary technologies can trigger for the far-off future?

This paper draws upon a design workshop that dealt with the concept of imagination and responsibility in design through exploring the theme of the future of education in China. At the workshop, fifty-six User Experience (UX) students from China were appointed a different technology to envision the education in 2030. The aim of the workshop was to reflect on the impact both these rising technologies and the external dynamic forces (e.g., demography and politics in China) might have on the products and services of the education of tomorrow, and most importantly, to investigate their effect on students' accountable decisions and reflective actions in and on design (Schön, 1983). This is a reflective paper based on empirical evidence that articulates a new attitude towards the use of creativity methods to stimulate anticipation in (non)design students.

\section{BACKGROUND}

\subsection{Creativity and imagination in the early stages of design}

Creativity is (among other cognitive capabilities such as strategic and critical thinking) a crucial factor of innovation, and has been recognized as a key element to discuss 21 st century challenges (Shalley and Gilson, 2017). Some argue that creativity should be attributed to the individual human mind (Niu and Sternberg, 2006). However, more voices rise to explain how social and contextual conditions influence individual and team creativity (Gilson et al., 2015). For instance, the Eastern perception tells that moral goodness (i.e., exceeding man's own needs and help to solve societal problems) is a necessary aspect of creativity (Niu and Sternberg, 2006). Creativity can be seen as a demonstration of new ways of thinking, feeling and acting that interrupt previous settled norms (Bailin, 1991). In this research, creativity is taken to refer to processes and individual or collective activities (e.g., defining problems and generating ideas) rather than merely focus on results (Gilson and Shalley, 2004).

Design thinking has been defined as a fundamental methodology to solving a problem in a creative manner on the premise that analytical thinking has not been sufficient (Brown, 2009; JohanssonSöldberg et al., 2013). The design thinking mindset (a divergent way of thinking) offers a framework to apply diverse methods that allow people to reframe the way in which they understand a problem and develop thoughts. It is argued to provide an organic flow of experience, or to make these experiences more meaningful and satisfying (Buchanan, 1992). The British Design Council, for instance, describes the design thinking process, called the 'Double Diamond', as having the following four distinct steps: 'Discover', 'Define', 'Develop' and 'Deliver'. To explore or 'Discover' an initial 
challenge, is most critical in this framework; this activity proceeds the 'Define' phase in which all gathered information is filtered and processed. Sequentially, during the 'Develop' phase several ideas are generated, which are prototyped and launched in the 'Deliver' phase (Design Council, 2005).

In industrial design engineering literature too, prescriptive process models put emphasis on the early stages of design development. The Innovation Cycle by Buijs and Valkenburg (2005) includes a reflection phase described as the 'strategic direction formulation'. This strategy, that gives companies a reason why they innovate, shapes the start of the actual development process: the design brief. Joore and Brezet (2015) aim at freeing designers from requirements and restrictions by looking out for desirable possibilities. Also, central point in the Vision in Product (ViP) approach by Hekkert and Van Dijk (2011) is the personal and subjective reflection that focuses on a series of context factors during the user-product interaction. However, by simultaneously thinking and feeling a certain situation more time is needed to see potentials instead of just constraints. Each design decision can afterwards be tied to the created visions, which makes them both a strong source of inspiration and a tool for evaluation (Hekkert et al., 2003). The benefit of a preliminary opportunity identification phase lies in the fact that the context for the product or service, which is often an entire system of complex social and cultural transformations, has already grown in the designer's mind.

Broadly speaking, creativity helps to visualize, experiment and materialize ideas with originality, novelty, usefulness and imagination. The concept also refers to the capacity to take decisions based on incomplete information (Corazza, 1996). Manzini and Cullars (1992) argue that imagining new scenarios for alternatives lifestyles is the most specific task of designers, and they do so by using their creative skills to visualize plausible and desired future situations that are largely hypothetical and undefined. Empathy and perspective-taking acts are important for these imaginative processes (Glăveanu and de Saint Laurent, 2015). Rather than being based on individual experiences, imagination is based on a collective whole (Glaveanu and de Saint-Laurent, 2015). Also, while making images of the future, elements from the past and the present are implemented in the future, or as Namier (1942) has put it, 'to imagine the past and remember the future' (Addis et al., 2007; Schacter and Madore, 2016). While people deal with the uncertainty of not knowing which future will happen, human imagination offers a tool to contextualize it (Abbey and Valsiner, 2005). Being able to anticipate contemporary challenges is an important dimension of responsible innovation (Stilgoe et al., 2013).

\subsection{Shifting towards responsible designers and futures}

A lot of effort has gone into the understanding and development of design processes and creativity (Csikszentmihalyi and Sawyer, 2014; Design Council, 2005; Shalley and Gilson, 2017). However, now, perhaps more than ever, designers face the challenge of using this knowledge for a collective long-lasting goal (Bezerra and Brasell-Jones, 2005). In this framework, a responsible designer is characterized as someone who questions the logic of our present society and the effects of design when at the same time considers scenarios and alternatives by evaluating materials, manufacturing processes, form and functionality (Leerberg, 2010). Shanks (1967) state that the role for a designer is to grasp the opportunities presented by new technologies, but to do so using a clear strategy and an overview of the implications caused by the respective changes. The designer should thus be a forwardlooking person who joins human issues, technology and business to boost the making of tomorrow's innovations (Feland et al., 2004).

Shaping the future lies at the heart of product development (Salovaara and Mannonen, 2015). In this quest designers are concerned with invention and judgment (Buchanan, 1992). In both aspects they have to take intellectual risks during decision-making that they normally only take when having explored different options (Lewis, 2006). Previously, ethical dilemmas about technological innovations were assessed after the developments, and concerned mainly the instrumentalist conception of technology (e.g., risks and costs) (Swierstra and Jelsma, 2006). However, when products and services are human made, humans are expected to make conscious and ethical choices about and during the course of its development. Both Bezerra (2005) and Swierstra (2006) and their colleagues mention how (engineers and) designers leave social responsibility to others, as they do not feel empowered to act as the agent of change they could be. Therefor, it is important at an early stage to train students to deal with 'ill-defined' problems or, with ambiguous situations of discovering and fulfilling a compelling need. They should be able to gather and interpret information and propose a solution (Manzini and Cullars, 1992). By doing so, students can develop personal and professional 
skills and take responsibility for the development of both the challenge and the solution (Feland et al., 2004). While design responsibility sometimes addresses an attitude towards the value of design (Leerberg, 2010), the authors broach the question to what extent ethical issues that come from the macro environment can inspire participants to explore and experiment in a workshop on the future of education.

Similar to design thinking methodology mentioned above, the futures studies approach addresses the increasingly complex challenges of today (Visser, 2006). While a user-centered approach of design thinking is suitable for incremental design in which consumers' own insights are a helpful input, in radical innovation the content more often than not is created by following a futures vision approach (Design Council, 2005). As a methodology futures studies exceed design thinking on the facet of accepting multiple plausible options (Visser, 2006). Futures studies' speculative aspect succeeds to probe diverse futures and their impact on society (Gatto and Mccardle, 2016). Considering that designers are asked to reflect and take responsibility in the creation of products and services for the future (Bezarra, 2005), their training is argued to benefit from methods of futures studies during the early design phase of 'Discovery' (Selin et al., 2004).

\section{WORKSHOP}

Different creativity-inducing methods were used to enrich the design workshop experience (Table 1). When the topic was announced participants were asked to undertake a P.E.S.T.E.L. analysis (Political, Economic, Sociological, Technological, Ecological/Environmental and Legal), an adaptation of the ETPS scanning tool invented by Harvard professor Francis Aguilar in 1967. The field of legal aspects (L) was replaced by the field of ethics (E), and so the acronym changed to 'P.E.S.T.E.E.'. The following three actions during the workshop included ways of addressing participants' narrative skills. For this, different media were explored to express stories that combine personal memories and feelings with more general events. The creative insights of participants who are currently not experienced (or do not have confidence to fully express their thoughts) may be subverted in favor of those who can (Kaufman and Beghetto, 2009). Therefore, the use of narratives is argued to be a suitable and accessible tool especially to non-designers (Svanaes and Seland, 2004).

Table 1. Overview of the workshop

\begin{tabular}{|c|c|}
\hline Step & Description of the workshop \\
\hline 1 & $\begin{array}{l}\text { The topic was defined as 'Education of the Future'. The future horizon was set to } 2030 . \\
\text { Participants in the process were identified as new master students UX at BNU. }\end{array}$ \\
\hline 2 & $\begin{array}{l}\text { Research through a P.E.S.T.E.E. analysis to identify external factors as potential drivers for } \\
\text { change and innovation. }\end{array}$ \\
\hline 3 & $\begin{array}{l}\text { On- and off-line search on historical and present evolutions were listed and visualized in a } \\
\text { technology roadmap. }\end{array}$ \\
\hline 4 & $\begin{array}{l}\text { Imagination exercise drawing on seven words, a) applying different media with (un)limited } \\
\text { resources, and b) going from abstract to specific situations. }\end{array}$ \\
\hline 5 & (Individual) storytelling exercise with pictures. \\
\hline 6 & $\begin{array}{l}\text { Social imagination exercise with an everyday object to demonstrate how their personal stories } \\
\text { intersect with history and globalization. }\end{array}$ \\
\hline 7 & $\begin{array}{l}\text { Brainstorm with trends: a) Exploration of a large amount of trends illustrated on a trend map. } \\
\text { b) Selection of six trends shaping future. c) Combination of minimum two trends into ideas. }\end{array}$ \\
\hline 8 & (Individual) imagination exercise using SCI-FI storytelling as stimulus. \\
\hline 9 & $\begin{array}{l}\text { Scenario exercise: a) Ranking scenario drivers in terms of both uncertainty and impact level. } \\
\text { b) Adopting a } 2 \times 2 \text { matrix structure to develop } 4 \text { scenarios. c) Refining each scenario's } \\
\text { storyline. }\end{array}$ \\
\hline 10 & $\begin{array}{l}\text { Communication of the scenarios and products or services: a persona, a storyboard, a } \\
\text { prototype, or a video, that would address a heterogeneous audience. }\end{array}$ \\
\hline
\end{tabular}

Subsequent to storytelling, a trend-injected interactive brainstorm was introduced which generate initial solutions. Later, the futures scenario task included three sub-activities: (a) ranking drivers in terms of uncertainty and impact on the future; (b) adopting a structure to develop four scenarios; and, (c) refining the storyline of each scenario. Before setting up the futures scenario exercise, students were asked to stimulate their imagination once more, this time starting from a peculiar short science 
fiction story with an open end. The final stage of the workshop was a presentation of both the unfolded visions for the future and suggestions for products and services within one possible future.

Students were given a methodology that could inspire them to tackle problems differently and have an open view on problem solving. They started with a guided look into the future context of education and simultaneously delved into an emerging technology that could be influential in that prospected world. This progress could be regarded as a transformation from a chaotic environment to the consensus provided by a specific concept (Buchanan, 1992).

Exploration through visualization was implemented in two ways: by making mind maps with images and words, and by illustrating future scenarios with personas or product concepts (Gill and Graell, 2016). Even though most of the participants of the workshop were novices in design, the expected outcome of each technique should have been feasible for all (Kilgore et al., 2007). The framework of the workshop (Figure 1) looks to the design model of Hekkert and Van Dijck (2011). Even in the early stages of design processes, several activities alternate between divergent and convergent thinking and between research and development.
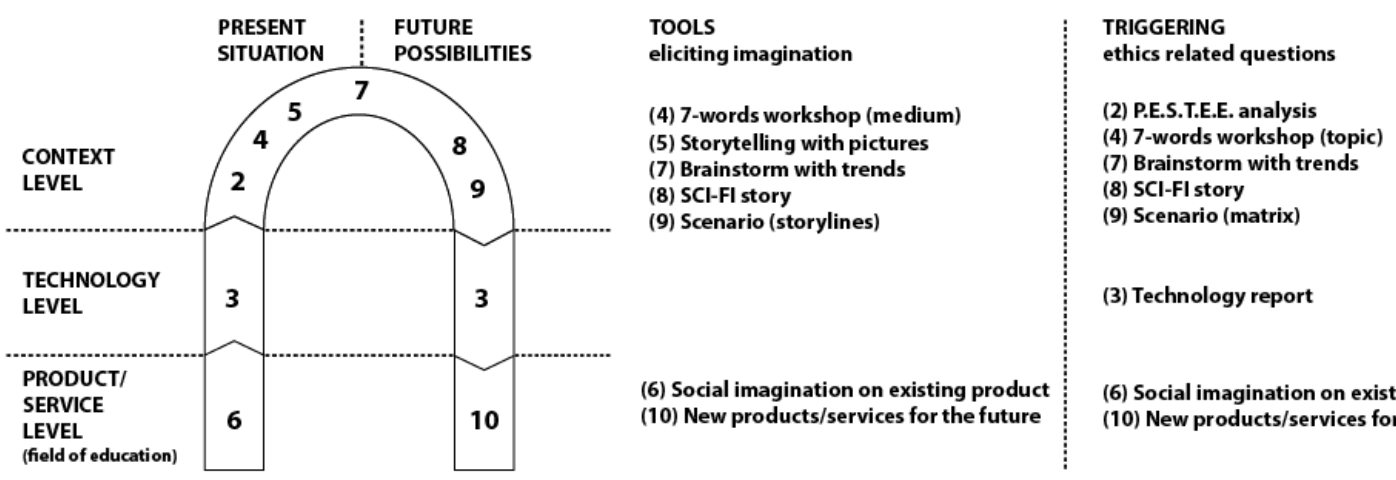

Figure 1. Framework of the workshop (adapted from Hekkert and Van Dijck, 2011). The numbers in the Figure refer to the steps from the workshop listed in Table 1.

Fifty-six Chinese students aged between twenty and thirty-seven years old participated in the 4-day workshop. Thirty-nine participants were female and seventeen were male. The students were divided into 11 groups of 5 to 6 people, and only two groups had a homogeneous gender composition. All groups had multidisciplinary teams (i.e., with different undergraduate degrees in psychology, literature and management science). Nineteen had working experience in areas such as human resources, data analysis or technical sales. Most of the students lacked substantial training in creative techniques with only five of them having a background in design, art or architecture. Nearly half of the students participated to a hands-on creative project two weeks prior to the workshop.

\subsection{Tools in the early design phase}

Since the mid-twentieth century, the velocity at which the evolutions occur at the cultural, economic, technologic and social level has become more apparent (Guemes-Castorena, 2009). These changes influence the environment that is the frame of reference on which all design decisions are based and therefore this context should be explored as a first step in a design process (Hekkert and Van Dijck, 2011). So, before starting to design the future of education, students were invited to develop a clear understanding of the future context during the 'Discovery' phase. Essential in this early stage is time to explore opportunities (Tschimmel, 2012). Figure 1 shows a 'bridge' enclosed by the present and the future context. Within this framework, research and analysis are the main activities to connect the 'now' with the 'later'. The connection promotes a continued two-way dialogue between a problem space and a solution space (Adams et al., 2003; Cross, 1997). In that respect, monitoring macroenvironmental factors gain importance (Gosselin and Tindemans, 2016). By scanning its surroundings, students get an impression of the topic of education. They get a chance to develop their capacity for empathy and improve their observation on circumstances. One of our aims was to let the participants consider opportunities instead of limitations and challenges instead of problems.

In the next assignment an overview of important past issues (or actions) regarding the explored technology is shown in a technological trajectory. Eleven different emerging technologies, e.g., 
artificial intelligence, block chain and Internet of things, were assigned to the 11 groups. Specifically, students completed an extrapolation-timeline to get inspired about where technology might move in the future and to understand links with parallel societal and economical structures. Likewise, trends identify the beginning of what might influence future human behavior, organizations or products, and are therefore a suitable tool for this identifying process (Brown, 2008). For this reason, the students were asked to choose six trends from a trend map composed by Richard Watson (2017) and to combine some of these tendencies as inspiration for ideation.

The next objective was to examine the interaction of two impactful and highly uncertain evolutions (Table 2). Selecting these evolutions was a crucial step and it was not based on what could lead towards a 'better' or a 'worse' outcome, allowing potentially more space for participants to make their own value judgments (Montgomery and Woebken, 2016; Raven and Elahi, 2015). The students' imagined scenarios for four quadrants of the matrix served as a foundation for the created products and subsequent services.

Table 2. The $X$ - and $Y$-axes, defined by teams $A$ to $K$, identify the alternative directions in which two high uncertain and impactful factors of the future might evolve

\begin{tabular}{|c|l|l|}
\hline & X-axis & Y-axis \\
\hline A & Individual vs. teamwork & Control: human vs. machine \\
\hline B & Limited vs. unlimited & Care: about all species vs. only about humans \\
\hline C & (Not documented) & (Not documented) \\
\hline D & No privacy vs. privacy highly protected & Wellbeing: public vs. commercial \\
\hline E & Emotional stimulation: low vs. high & Human autonomy: low vs. high \\
\hline F & Temporary vs. permanent & Inequality: low vs. high \\
\hline G & Frequency: low vs. high & Ease of use: low vs. high \\
\hline H & Virtual vs. real & Rational vs. emotional \\
\hline I & Context: virtual vs. physical & Individualism vs. collectivism \\
\hline J & Efficiency: low vs. high & Adaptability: low vs. high \\
\hline K & Immaterial vs. material & Users: special vs. common \\
\hline
\end{tabular}

\subsection{Multimedia imagination exercises}

Different imagination exercises were introduced to stimulate creativity. The inspiration was initially provoked by external stimuli, such as words, images and science fiction. However, with the use of an internal catalyst they created descriptive and illustrative images (An and Youn, 2018). At first, through the employment of the 'Seven words' method (developed by Beijing-based artist Alessandro Rolandi), participants were asked to sketch their understanding of the following concepts: authority, autonomy, territory, border, communication, desire and transformation (Rolandi, 2018). Afterwards, the same keywords were the motive to create both 3D-artifacts and videos. At that moment, students were allowed to manipulate random objects, the space of the workshop and their own bodies to express their reflections. A second assignment stimulated the storytelling capacities of the participants through encounters with self-taken pictures (Candy, 2013). Storytelling is central in creativity and design processes, because it is applicable to train both divergent and convergent thinking (Raven and Elahi, 2015; Selin et al., 2015). Stories can be useful tools in several activities of the design process including the actual development, the design communication, documentation and evaluation (Parrish, 2006). Thirdly, students were asked to think critically about social life and to recognize that individuals' needs, values and behaviors do not occur in a vacuum but are influenced by place and time (Kaufman, 1997). A smartphone chosen as the discussed object, was identified and analyzed in the context of the participants' own social reality. Furthermore, stakeholders from various cultural perspectives and historical connotations were debated. Finally, students were asked to formulate a 'cause' and an 'effect' of the unfamiliar phenomena described in the science fiction short story 'In the drought' by Ursula K. Le Guin (1996). Science fiction cannot only be used to explore futuristic urban planning. It can also be inspirational for the development of new products and services (Collie, 2011). 


\section{STUDENT REFLECTIONS}

We filtered four main thoughts that according to students could shape the future of education and summarize some of their final ideas. First, the attention that emotional intelligence gets nowadays was not present twenty years ago (Xiaohong, 2016). Although it is seen as an important aspect of a person's comprehensive quality, (college) students lack several abilities in the new era: to adapt to new environments, to handle interpersonal relationships and to self-manage (Zhuoxin, 2018). The education of emotional intelligence is not a one-time process, neither is its training limited to the school environment (Zhuoxin, 2018). For example, the 'Dream object', which was designed during the workshop, is a device that creates an object from our dreams or representations of our unconscious memories. The idea behind is: "When you wake up, the object reminds you of your childhood ambition". Second, in recent years the interest for gamification learning and its connected teaching philosophy of learning and entertainment has grown (Shiming and Tian, 2018). Although these trigger students' individual discovery ability, learning motivation and interest, doubts rise about a short-term feasibility (e.g., qualitative resources and experienced teachers) (Lu and Junjie, 2018). A studyprogram-selecting-game was created. This tool (Figure 2) would advise youngsters who have difficulties to select a study program that they would like and would lead to an interesting job.
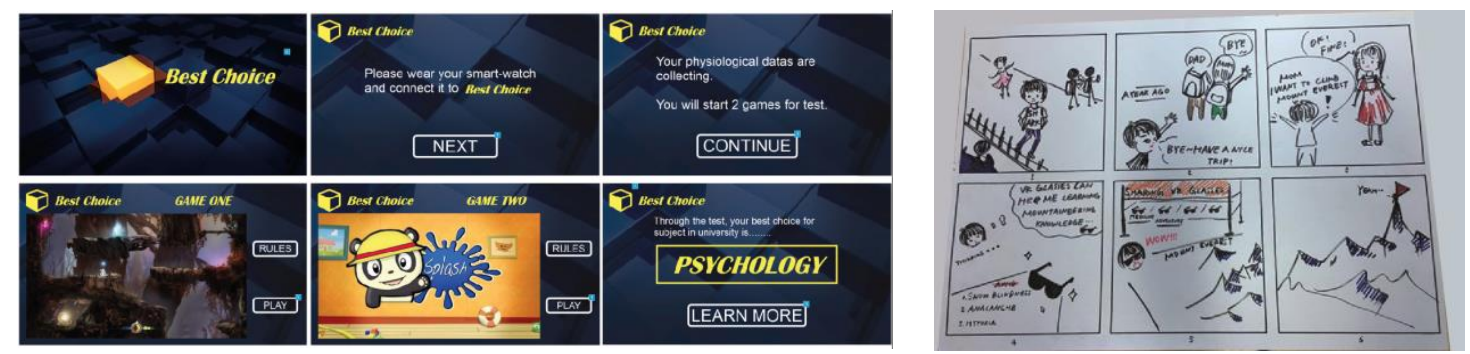

Figure 2. Study-program selection game (left).

Figure 3. A storyboard on VR experience (right).

Third, understanding oneself correctly is a condition for autonomy (Taohua, 2016). In the light of education, this implies knowing your interests, mastering your knowledge and managing your study habits (Yufeng, 2018). When teaching students to learn independently, some conditions can be adjusted towards more freedom and afterwards the driving force to study and set own goals might come from the students themselves (Yufeng, 2018). Is concept 'virtual piano room' the future? Imagine an invisible piano teacher who can talk to you anywhere and anytime: he motivates you while playing and assists you during assignments, yet, he also controls whether you to have been practicing enough. Lastly, the contradiction between virtual and real can be interpreted as the difference between online and offline education. In contemporary learning, due to rapid technological development and state support, online teaching has earned wide acceptance (Xin and Lijun 2018). New tools and communication platforms are designed to interact in a flexible, efficient and convenient way with the intention to imitate the best practices of offline education (e.g., close follow-up, gathering with peers, variation in evaluation and teaching methods). Figure 3 shows a student learning how to reach the summit of Mount Everest by virtual trainings on the expected situations. In contrast, envision a severe and controlled world where creativity is forbidden; 'John' cannot answer his curious daughter's questions until he employs 'Nano', a virtual (g)host living in a microchip.

\section{DISCUSSION AND FURTHER WORK}

Although the workshop was for most of the participants an introduction to design and creativity, the underlying idea was to let students discover that they can be creative and at the same time act responsibly. Reflections on changing circumstances were introduced in a design-for-anticipation project. Several actions that can be appreciated as responsible were described above: decision-making based on discussing imagined alternatives, extensive problem exploration, monitoring evolutions from different perspectives and long term strategy thinking. However, the inevitable consequences of the designed products and services on the future context stayed underexposed during the workshop. Students could be encouraged to propose alternatives of undesired side effects of their design concepts (Bailey et al., 2016). Imagining alternative scenarios, through, for example, projecting on the future, could bring up important and largely uncertain insights from the macro-environment context, that is, the socio-cultural, economical, ecological, political, ethical and technological factors of the future. 
Although innovations are often seen as a pressure on ethical values, moral concerns about these progressions can also become a driving force. For instance, by challenging students to work out of their comfort zone (of current knowledge domain and experience), it was expected to bring about discovery of the existence and usefulness of multiple perspectives. Lastly, special emphasis in the workshop was given to the formulation of moral dilemmas. Established ethical issues, like privacy and intellectual property remain relevant. However, many more possible ethics will be questioned with the growth of new technical developments (Reijers et al., 2018; Stahl, 2013). Will future (machinelearning) education strengthen or weaken individual characteristics of students? Will children, who do not go to school, be (psychologically) missing something? Should (VR/AR) technology simulate bloody scenes from cruel historical events? After investing in (VR) technology should the teachers' salary be reduced when the financial recourses stay the same? Certainly, design cannot remain neutral (Bezerra and Brasell-Jones, 2005). Ethical issues coming from technological innovation and contextual impacts can inspire and empower design. In forthcoming events we intend to investigate further into the effect of the workshop on students' level of creativity and ethics.

\section{REFERENCES}

Abbey, E. and Valsiner, J. (2005), "Emergence of meanings through ambivalence", Forum: Qualitative Social Research, Vol. 6 No. 1. http://dx.doi.org/10.17169/fqs-6.1.515

Adams, R. S., Turns, J. and Atman, C., (2003), "Educating effective engineering designers: The role of reflective practice", Design Studies, Vol. 24 No. 3, pp. 275-294. http://dx.doi.org/10.1016/S0142-694X(02)00056-X

Addis, D. R., Wong, A. T. and Schacter, D. L. (2007), "Remembering the past and imagining the future: common and distinct neural substrates during event construction and elaboration", Neuropsychologia, Vol. 45 No.7, pp. 1363-1377. https://doi.org/10.1016/j.neuropsychologia.2006.10.016

An, D. and Youn, N. (2018), "The inspirational power of arts on creativity", Journal of Business Research, Vol. 85, pp. 467-475. https://doi.org/10.1016/j.jbusres.2017.10.025

Bailey, M., Spencer, N., Bentham, A., Baylis, B. and Sams, P. (2016), "What on earth is responsible innovation anyway? (And how to make it happen)," Proceedings of the 18th International Conference on Engineering and Product Design Education, pp. 234-239.

Bailin, S. (1991), "Rationality and intuition”, Philosophical Inquiry in Education, Vol. 4 No. 2, pp. 17-26.

Bennett, S. and Maton, K. (2010), "Beyond the 'digital natives' debate: Towards a more nuanced understanding of students' technology experiences", Journal of computer assisted learning, Vol. 26 No. 5, pp. 321-331. https://doi.org/10.1111/j.1365-2729.2010.00360.x

Bezerra, C. and Brasell-Jones, M. (2005), "Design Responsibility in Global Open Societies", Conference Proceedings Joining Forces International Conference on Design Research. University of Art and Design: Helsinki.

Brown, T. (2009), Change by Design: How Design Thinking Transforms Organizations and Inspires Innovation, Harper Collins Publishers.

Buchanan, R. (1992), “Wicked problems in design thinking”, Design issues, Vol. 8 No. 2, pp. 5-21. https://doi.org/10.2307/1511637

Buijs J. A. and Valkenburg A. C. (2005), Integrale Productontwikkeling. Boom Koninklijke Uitgevers.

Candy, S. (2013), "Time Machine/Reverse Archaeology", Retrieved, Vol. 11 No. 11.

Collie, N. (2011), "Cities of the imagination: Science fiction, urban space, and community engagement in urban planning", Futures, Vol. 43 No. 4, pp. 424-431. https://doi.org/10.1016/j.futures.2011.01.005

Corazza, G. E. (2016), "Potential originality and effectiveness: The dynamic definition of creativity", Creativity Research Journal, Vol. 28 No. 3, pp. 258-267. https://doi.org/10.1080/10400419.2016.1195627

Cross, N. (1997), "Descriptive models of creative design: application to an example", Design studies, Vol. 18 No. 4, pp. 427-440. https://doi.org/10.1016/S0142-694X(97)00010-0

Csikszentmihalyi, M. and Sawyer, K. (2014), "Creative insight: The social dimension of a solitary moment", The systems model of creativity, pp. 73-98. Springer, Dordrecht. https://doi.org/10.1007/978-94-017-9085-7_7

Design Council (2005), "The double diamond design process model", https://www.designcouncil.org.uk

Feland, J. M., Leifer, L. J. and Cockayne, W. R. (2004), "Comprehensive design engineering: Designers taking responsibility", International Journal of Engineering Education, Vol. 20 No. 3, pp. 416-423. https://doi.org/0949-149X/91

Gatto, G. and Mccardle, J. (2016), "The designer and the scientist: The road to inspire transdisciplinary synergies", Proceedings of the 18th International Conference on Engineering and Product Design Education (E and PDE16), DS 83, pp. 468-473.

Gill, C. and Graell, M. (2016), "Teaching design thinking: Evolution of a teaching collaboration across disciplinary, academic and cultural boundaries", Proceedings of the 18th International Conference on Engineering and Product Design Education (E and PDE16), DS 83, pp. 34-39. 
Gilson, L.L. and Shalley, C. E. (2004), “A little creativity goes a long way: An examination of teams’ engagement in creative processes”, Journal of management, Vol. 30 No. 4, pp. 453-470. https://doi.org/10.1016/j.jm.2003.07.001

Gilson, L. L. and Madjar, N. (2011), "Radical and incremental creativity: Antecedents and processes", Psychology of Aesthetics, Creativity, and the Arts, Vol. 5 No. 1, p. 21.

Gilson, L. L., Lim, H. S., Litchfield, R. C. and Gilson, P. W. (2015), "11 Creativity in Teams: A Key Building Block for Innovation and Entrepreneurship", The Oxford handbook of creativity, innovation, and entrepreneurship, p. 177.

Glăveanu, V. P. and de Saint Laurent, C. (2015), "Political Imagination, Otherness and the European Crisis", Europe's journal of psychology, Vol. 11 No. 4, pp. 557-564. https://doi.org/10.5964/ejop.v11i4.1085

Gosselin, D. and Tindemans, B. (2016), Thinking Futures: Strategy at The Edge of Complexity and Uncertainty, Lannoo Meulenhoff-Belgium.

Guemes-Castorena, D. (2009), "Megatrend methodology to identify development opportunities". PICMET Proceedings 6, Portland International Conference, pp. 2391-2396.

Hekkert, P., Mostert, M. and Stompff, G. (2003), "Dancing with a machine: a case of experience-driven design", Proceedings of the international conference on Designing pleasurable products and interfaces, pp. 114119. ACM. https://doi.org/10.1145/782896.782925

Hekkert, P. and Van Dijk, M. (2011), Vip-Vision In Design: A Guidebook for Innovators, BIS Publishers.

Johansson-Söldberg, U., Woodilla, J. and Çetinkaya, M. (2013), "Design thinking: past, present and possible futures", Creativity and innovation management, Vol. 22 No. 2, pp. 121-146. https://doi.org/10.1111/caim.12023

Joore, P. and Brezet, H. (2015), “A Multilevel Design Model: the mutual relationship between product-service system development and societal change processes”, Journal of Cleaner Production, Vol. 97, pp. 92-105. https://doi.org/10.1016/j.jclepro.2014.06.043

Kaufman, P. (1997), "Michael Jordan Meets C. Wright Mills: Illustrating the Sociological Imagination with Objects from Everyday Life", Teaching Sociology, Vol. 25 No. 4, pp. 309-314. https://doi.org/10.2307/1319299

Kaufman, J.C. and Beghetto, R. A. (2009), "Beyond big and little: The four c model of creativity", Review of general psychology, Vol. 13 No. 1, p. 1. https://doi.org/10.1037/a0013688

Kilgore, D., Atman, C. J., Yasuhara, K., Barker, T. J. and Morozov, A. (2007), “Considering Context: A Study of First-Year Engineering Students” Journal of Engineering Education, Vol. 96 No. 4, pp. 321-34. https://doi.org/10.1002/j.2168-9830.2007.tb00942.x

Le Guin, U. K. (1996), Unlocking the Air: Stories. Harper Collins.

Leerberg, M., Riisberg, V. and Boutrup, J. (2010), "Design responsibility and sustainable design as reflective practice: An educational challenge”, Sustainable Development, Vol. 18 No. 5, pp. 306-317. https://doi.org/10.1002/sd.481

Lewis, T. (2006), "Creativity: A framework for the design/problem solving discourse in technology education", Journal of technology education, Vol. 17 No. 1, pp. 36.

Lu, Z. and Junjie, S. (2018), "The study of gamification learning theory based on the perspective of learning experience", E-education Research, Vol. 39 No. 06, pp. 11-20. (*)

Manzini, E. and Cullars, J. (1992), "Prometheus of the Everyday: The Ecology of the Artificial and the Designer's Responsibility”, Design Issues, Vol. 9 No. 1, pp. 5-20. https://doi.org/10.2307/1511595

Markman, K. D., Klein, W. M. and Suhr, J.A. (2012). Handbook of Imagination and Mental Simulation, Psychology Press.

Montgomery, E.P. and Woebken, C. (2016), Extrapolation Factory - Operator's Manual: Publication Version 1.0, CreateSpace Independent Publishing Platform.

Namier, L. B. (1942) "Conflicts: Studies in Contemporary History”, 69-70.

Niu, W. and Sternberg, R. J. (2006), "The philosophical roots of Western and Eastern conceptions of creativity", Journal of Theoretical and Philosophical Psychology, Vol. 26 No. 1, p. 18.

Parrish, P. (2006), "Design as storytelling”, TechTrends, Vol. 50 No. 4, pp. 72-82.

Raven, P. G. and Elahi, S. (2015), "The New Narrative: Applying narratology to the shaping of futures outputs", Futures, Vol. 74, pp. 49-61. https://doi.org/10.1016/j.futures.2015.09.003

Rolandi, A. (2018), Retrieved December 2, 2018 from http://www.socialsensibility.org/project-16-7-Words

Reijers, W., Wright, D., Brey, P., Weber, K., Rodrigues, R., O’Sullivan, D. and Gordijn, B. (2018), “Methods for Practising Ethics in Research and Innovation: A Literature Review, Critical Analysis and Recommandations", Science and Engineering Ethics, Vol. 24 No. 5, pp. 1437-1481.

Salovaara, A. and Mannonen, P. (2005), "Use of Future-Oriented Information in User-Centered Product Concept Ideation", IFIP Conference on Human-Computer Interaction, pp. 727-740.

Schacter, D. L. and Madore, K. P. (2016), "Remembering the past and imagining the future: Identifying and enhancing the contribution of episodic memory", Memory Studies, Vol. 9 No. 3, pp. 245-255. https://doi.org/10.1177/1750698016645230

Schön, D.A. (1983) The Reflective Practitioner: How Professionals Think in Action, Basic Books, New York. 
Shalley, C. E., Gilson, L. L. and Blum, T. C. (2000), "Matching creativity requirements and the work environment: Effects on satisfaction and intentions to leave", Academy of management journal, Vol. 43 No. 2, pp. 215-223. https://doi.org/10.5465/1556378

Shalley, C. E. and Gilson, L. L. (2017), "Creativity and the management of technology: Balancing creativity and standardization", Production and Operations Management, Vol. 26 No. 4, pp.605-616. https://doi.org/10.1111/poms.12639

Shiming, Z. and Tian, W. (2018), “An Empirical Study of Gamification Learning in China’s Basic Education Stage", Digital Education, Vol. 22, pp. 50-55. (*)

Selin, C., Kimbell, L., Ramirez, R. and Bhatti, Y. (2015), "Scenarios and design: Scoping the dialogue space", Futures, Vol. 74, pp. 4-17. http://dx.doi.org/10.1016/j.futures.2015.06.002

Shanks, M. (1967), The Innovators: The Economics of Technology, Penguin Books, Baltimore.

Stahl, B.C. (2013), "Virtual suicide and other ethical issues of emerging information technologies", Futures, Vol. 50, pp. 35-43. http://dx.doi.org/10.1016/j.futures.2013.03.004

Stilgoe, J., Owen, R. and Macnaghten, P. (2013), "Developing a framework for responsible innovation", Research Policy, Vol. 42 No. 9, pp. 1568-1580. https://doi.org/10.1016/j.respol.2013.05.008

Svanaes, D. and Seland, G. (2004), "Putting the users center stage: role playing and low-fi prototyping enable end users to design mobile systems", Proceedings of the SIGCHI conference on Human factors in computing systems, pp. 479-486.

Swierstra, T. and Jelsma, J. (2006), "Responsibility without moralism in techno scientific design practice", Science, technology, and human values, Vol. 31 No. 3, pp. 309-332. http://doi.org/10.1177/0162243905285844

Taohua, L. (2016), "Factors Affecting and Countermeasures the Development of home-school Students' Learning Autonomy after Class", The Chinese Teacher, Vol. 6, pp.75. (*)

Tschimmel, K. (2012), "Design Thinking as an effective Toolkit for Innovation”, ISPIM Conference Proceedings.

Visser, W. (2006), "Designing as construction of representations: A dynamic viewpoint in cognitive design research”, Human-Computer Interaction, Vol. 21 No. 1, pp. 103-152. https://doi.org/10.1207/s15327051hci2101_4

Watson, R. (2017), "Mega trends and technologies 2017-2050”. Retrieved December 10, 2017 from https://nowandnext.com/PDF/Mega\%20Trends\%20and\%20Technologies\%202017-2050\%20(Print).jpg

Xiaohong, W. (2016), “A Study on Strategies of College Students’ EQ Cultivation”, Master of Education thesis, Sichuan International Studies University. (*)

Xin, C. and Lijun N. (2018), "The Battle of Online and Offline Modes: Where Does College Education Go", China Economist, Vol. 8, pp. 184-185. (*)

Yufeng, X. (2018), “Analysis of the Lack of Reasons for Pupils’ Learning Initiative and its Cultivation”, $P C$ Fan, Vol. 7, pp. 196. (*)

Zhuoxin, X. (2018), "Research on the Emotional Education Path of College Students from the Perspective of Harmonious Personality", The Home of Drama, Vol. 279, pp. 193. (*)

(*) translated from Chinese.

\section{ACKNOWLEDGMENTS}

We thank all participants, the students who assisted, artist Alessandro Rolandi, Dr. Peter Conradie, and the Belgian province West-Vlaanderen, who provided a grant for the travel costs to China. 